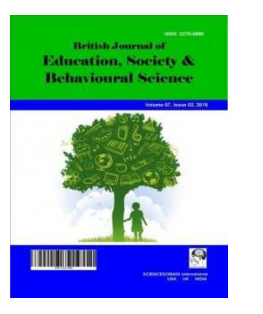

\title{
Effectiveness of Learning Cycle Models on Nigerian Senior Secondary Students' Anxiety towards Chemistry
}

\author{
Kehinde A. Alebiosu', Jumoke Bukola Bilesanmi-Awoderu ${ }^{1}$ \\ and Olajumoke Shakirat Oludipe ${ }^{2^{\star}}$ \\ ${ }^{1}$ Department of Science and Technology Education, Faculty of Education, \\ Olabisi Onabanjo University, Ago-Iwoye, Nigeria. \\ ${ }^{2}$ Department of Science and Technology Education, Faculty of Education, \\ Lagos State University, Ojo, Lagos, Nigeria.
}

\begin{abstract}
Authors' contributions
This work was carried out in collaboration between all authors. Author KAA designed the study, performed the statistical analysis, wrote the protocol and the first draft of the manuscript. Authors JBBA and OSO managed the analyses of the study. Author OSO managed the literature searches. All authors read and approved the final manuscript.

Article Information

DOI: 10.9734/BJESBS/2017/34012

Editor(s):

(1) Shao-I Chiu, Taipei College of Maritime Technology of Center for General Education, Taiwan.

Reviewers:

(1) Sreehari Ravindranath, Christ University, India. (2) Atila Yildirim, Necmettin Erbakan University, Turkey. (3) Şehriban Koca, Mersin University, Turkey. Complete Peer review History: http://www.sciencedomain.org/review-history/19406
\end{abstract}

Original Research Article

Received $9^{\text {th }}$ May 2017 Accepted $2^{\text {nd }}$ June 2017 Published $8^{\text {th }}$ June 2017

\section{ABSTRACT}

Aims: The method of teaching Chemistry in Nigerian classrooms has given it an image of being a subject with a body of abstract ideas, giving room for manifestation of anxiety towards the subject at the secondary school level. It is within this context that this study investigated the impact of $5 \mathrm{E}$ and PDEODE Learning Models on students' anxiety towards senior secondary Chemistry.

Study Design: Quasi experimental pre-test - post-test - control group design was used by the researchers to carry out the study.

Place and Duration of Study: STED department, faculty of education, Olabisi Onabanjo University, Ago-Iwoye and.STED department, faculty of education, Lagos State University, Ojo, South-west, Nigeria, between March 2013 and October 2014. 
Methodology: The treatments were at two levels: Learning Cycle models (PDEODE and 5E) and conventional lecture method, which was the control group. The moderating variables were gender (male and female) and cognitive style (field dependent and field independent). Total number of one hundred and eighty eight students (188) obtained from the intact classes of the three selected senior Secondary Schools in South-west Nigeria participated in the study. Chemistry Anxiety Rating Scale (CARS) and Group Embedded Figure Test (GEFT) were the main instruments used to collect data from students. Descriptive statistics and Analysis of Covariance (ANCOVA) were used to analyze the data collected. Also Multiple Classification Analysis (MCA) was used to determine the magnitude of the mean anxiety scores of students exposed to the different treatment conditions.

Results: The results of this study revealed that there was a significant difference $\left(F_{(2,175)}=13.659\right.$, $P<.05)$ in the post-test mean Chemistry anxiety scores of the students after exposure to the different instructional strategies. The students' post-test mean Chemistry anxiety scores after exposure to the different instructional strategies varied significantly $\left(F_{(2,175)}=3.879, P<.05\right)$, between the sampled field dependent and field independent secondary school students. However, no significant main effect of gender and cognitive style on students' Chemistry anxiety was found. The independent and moderator variables jointly accounted for $40.4 \%$ of the variation in their Chemistry anxiety scores.

Conclusion: This study concluded that exposing students to the PDEODE learning model led to reduced anxiety in Chemistry than the $5 \mathrm{E}$ learning model and the conventional method. It was therefore recommended that teachers be trained in the use of conceptual change model such as PDEODE learning model in the teaching and learning of Chemistry to reduce Chemistry anxiety. Also, teachers should not discriminate between any possible cognitive styles - gender combinations when using PDEODE strategy in the classroom.

Keywords: Learning cycle models; students' anxiety; cognitive-style; gender.

\section{INTRODUCTION}

The current interest in science education has raised important issues as to why some Nigerian students have turned away from the study of science in secondary schools. Concerns have been raised regarding declining enrolments in upper level (Chemistry, Physics and Biology) science courses; the decline of interest in pursuing science-related careers [1]. The reluctance, and sometimes even fear individuals express when laded with science-related problems.

Affective factors have emerged as vital factors affecting success and persistence in science subjects [2-4]. Critical among these is students' anxiety towards chemistry [5-9]. One of the purposes of chemistry education is to develop students' positive attitudes towards this subject in the school curriculum [10]. However, despite its acceptance as an important and fundamental science subject, the current perceptions held by several students contradict its real nature [6]. According to [11] anxiety is one of the fundamental sensations of human beings. It is a negative mood state characterized by bodily symptoms of physical tensions and by apprehension about the future. Everyone become anxious to different degrees when they are worried or frightened. However, being anxious might be beneficial to motivate students to bear responsibility for their learning, at the same time anxiety caused by excessive stress has a negative impact on the learning and performance of students [5].

The secondary school level is the stage at which students' interest, attitude and anxiety towards learning science (chemistry) can either be developed or marred. It is a stage when students are expected to show understanding, make generalization, and express their opinion on several issues and concepts. For these to be achieved, meaningful and effective learning of science, good instructional strategies among other factors are required. Science education reforms emphasize teaching students in an "inquiry-based" fashion; a method that bears enormous similarity to how scientists practice science as opposed to how they learn it in school. In achieving this, science education researchers have turned their gaze in a number of directions in search of relevant tools and resources. They include; Computer Assisted Instruction [12,13], Hands-on Minds-on [14], Concept Mapping [15], Cooperative learning [16], Questioning \& Answering [17]. They all found that each of the strategies have significant impact on the cognitive achievement of students, 
however, the cognitive achievement of students in external examinations is still poor. It then becomes clear that there is need to seek other approaches of teaching that will be studentcentered, involving student-student interaction, and make learning more meaningful by focusing on common day to day practices, to improve affective learning outcomes.

The Science Teachers Association of Nigeria (STAN) National Chemistry Workshop [18] on linking school chemistry with learners' day-to-day activities, aimed at identifying how chemistry concepts could be linked with learners' day-today practices and effective methods of teaching them to enhance learning outcomes in chemistry. The following observation and recommendations were made: The workshop observed that the way chemistry teaching is being handled in our classrooms makes it alien to learners. As such, links with common day-to-day activities should be incorporated into lesson plans to change this trend. Teachers should relate learning task to learners' immediate environment and needs to elicit their interest in the subject; Teachers should at the entry point during chemistry teaching, provide expositions on common day-today practices that revolve round chemistry.

Several other reasons have been given by researchers for incorporating everyday-life experiences and focusing on everyday-life applications of science. Every day-life experiences are a way to make science meaningful to students [19]. If it is wished to educate students as scientifically literate citizens, everyday-life theme related to science is necessary [20]. It is also an argument about constructivist view on learning, in which students' alternative conceptions derived from their day-today experiences before the classroom instructions, has been seen as a starting point in teaching [21]. Isolating the school science from students' everyday-life could make students develop two unconnected knowledge systems related to science: one is used to solve science problems in schools, and the other is used for their everyday-lives [22]. One of the factors that make learnt things permanent is connecting them with daily life [23].

In an effort to promote conceptual understanding in chemistry classrooms, and further applications in everyday situations leading to improved learning outcome in chemistry, this study wishes to emphasize on this issue in teaching chemistry, by assessing the effectiveness of three types of classroom instructions, the conceptual understanding 5E (Engagement, Exploration, Explanation, Elaboration, Evaluation) learning model, the conceptual change PDEODE (Predict, Discuss, Explain, Observe, Discuss, Explain) learning model, and conventional instruction, on the degree to which students understand chemical concepts and use them for interpreting phenomena in their everyday-life, thus reducing possible anxiety. The 5E Learning model is based on constructivism theory and Piaget's development theory (Intellectual development theory), enhancing learners' abilities to discover new knowledge by using inquiry approach. It is seen as an effective hands-on, minds-on, guided inquiry-based scientific pedagogy, especially for enhancing conceptual understanding [24]. The 5E Learning model consists of five phases: Engagement, Exploration, Explanation, Elaboration and Evaluation [25]. It is a teaching and learning procedure consistent with the privileged status of inquiry, deviating from the teacher centered approach to the student centered learning technique. It has been found to cause significantly better acquisition of scientific conceptions related to states of matter and solubility [26] and photosynthesis and respiration in plants [27]. It has also been found that having students exposed to learning activities in 5E model enhanced students' scientific performances and positive perceptions towards the learning activities [28].

The PDEODE strategy is a conceptual change model first proposed by [29]. According to [22], it is an important teaching strategy in which there is an atmosphere that supports discussion and diversity of views. It is believed that it can be used as a vehicle in helping students make sense of everyday situations. This consists of six steps: Prediction: P; Discuss: D; Explain: E; Observation: O; Discuss: D; Explain: E. Researchers have reported the positive impact of PDEODE learning model as a pedagogical strategy on learning outcomes within different learning context. It has been found to enhance better identification of students' preconceptions and conceptual change in students' understanding of the concept of evaporation and condensation, and also enable students to retain their new conceptions in their long-term memory $[30,31]$. It has also been found that having students learn within PDEODE model make them have better results in physics achievement and scientific thinking skills [32], enhanced mathematical thinking, understanding and retention of mathematical concepts [33]. 
These research reports are mainly foreign based, it might therefore be necessary to test the efficacy of these models in an environment like Nigeria. Literature also shows that some of these previous studies investigated the efficacy of a model over the conventional method, but this study is aimed at testing the effects of two models of learning over the conventional teaching method. This study investigated the effects of two learning models (5E and PDEODE) on senior secondary school students' anxiety towards chemistry. The moderating effects of gender and cognitive style on students' anxiety towards chemistry were also investigated.

\subsection{Research Question}

1. Would there be any difference in the pre and post-test anxiety scores of students taught within the different strategies (5E, PDEODE \& Conventional Method)?

2. Would there be any difference in the pre and post-test anxiety scores of students taught within the different strategies (5E, PDEODE \& Conventional Method) according to gender?

3. Would there be any difference in the pre and post-test anxiety scores of field dependent and field independent students taught within the different strategies (5E, PDEODE \& Conventional Method)?

\subsection{Hypotheses}

$\mathrm{Ho}_{1}$ : There is no significant main effect of the use of 5E and PDEODE Learning Models and Conventional method on senior secondary school students' anxiety towards Chemistry.

$\mathbf{H o}_{2}$ : There is no significant main effect of gender on senior secondary school students' anxiety towards Chemistry.

$\mathrm{Ho}_{3}$ : There is no significant main effect of cognitive style on senior secondary school students' anxiety towards Chemistry.

$\mathrm{Ho}_{4}$ : There is no significant interaction effect of the use of $5 \mathrm{E}$ and PDEODE Learning Models, conventional method and gender on senior secondary school students' anxiety towards Chemistry.

$\mathrm{Ho}_{5}$ : There is no significant interaction effect of the use of $5 E$ and PDEODE Learning Models, conventional method and cognitive style on senior secondary school students' anxiety towards Chemistry.

\section{METHODOLOGY}

This study employed the $3 \times 2 \times 2$ quasiexperimental design. This implies that the design included three instructional groups: experimental groups; 5E and PDEODE Learning models and the conventional method (control group); cognitive style at two levels - field- dependent and field- independent; and gender at two levelsmale and female. The target population for this study was the Senior Secondary I (SSI) science students in Education District III area of Lagos State, South/West Nigeria. The sample for this study was one hundred and eighty eight SSS I science students from three coeducation senior secondary schools, selected from a total of twenty- four senior secondary schools in Epe, Eredo and Ibeju-lekki Local Education Zones of Lagos State Education District III area of Lagos State, South/West Nigeria. Selection of the schools was dependent on the availability of Chemistry teachers, the distance of the schools to one another in order to remove contamination effect and willingness of school principals, teachers and students to cooperate and participate in the study. The chemistry topics used during classroom teaching were three topics (Separation techniques, Acids, Bases and Salts, Water) in Chemistry selected from the second term scheme of work. This was necessary to make sure that students had not been exposed to those topics before the experiment.

\section{INSTRUMENTATION}

In order to collect data for the study, the following instruments were validated and used:

\subsection{The Group Embedded Figure Test (GEFT)}

The Group Embedded Figure Test (GEFT) was developed by [34] in America and it was found by the authors to have a reliability coefficient of 0.82 using Spearman Brown prophecy formula on a sample of 80 female and 97 male. This was used in this study to determine the students' measure of field dependency and independency. Field dependency - independency refers to the extreme of the cognitive style continuum. Therefore, the higher the score on GEFT, the more field independent an individual is. Each respondent received this, containing 25 complex geometric designs and on the last page, the eight sample figures. There are 3 sections consisting of 7,9 , and 9 items respectively. The first section 
was for practice. The eight sample figures each to be identified by a letter cannot be viewed at the same time as the complex designs. The test score of individual sampled student represented the total number of figures correctly located. Thus, those that scored between 1 and 9 in this GEFT test were categorized as field dependent, while those that scored between 10 and 18 were categorized as field independent. This was administered on a sample of students, different from the schools selected for the study, to determine the reliability in Nigerian context; a Cronbach's alpha of 0.87 was obtained. This index showed an evidence of internal consistency.

\subsection{The Chemistry Anxiety Rating Scale (CARS)}

The Chemistry Anxiety Rating Scale (CARS) originally designed by [6]. Adapted to this study environment, the CARS consisted of fifteen (15) items meant to assess students' anxiety in learning chemistry. For each of the items, participants were required to use a scale of 1-4 to rate their level of anxiety, with 1 being strongly disagree and 4 being strongly agree. The minimum score on each of the fifteen items was one and the maximum score for the whole test was sixty-four. The instrument was administered on a sample of students, different from the schools selected for the study; A Cronbach's alpha of 0.78 was obtained. This index showed an evidence of internal consistency.

\subsection{Intervention Process}

There were three phases of data collection. These were the pre-test - first one week, treatment - eight weeks, the post-test - one week. Three periods of 40 minutes each were spent each week for the six weeks. There was no alteration on the time-table allocated for chemistry by the school, i.e. the periods were in line with the schools' time-tables. During the lessons, the teacher presented the topic and the instructional materials required. $\mathrm{He}$ listed the instructional objectives and further linked previous knowledge with the new material explicitly explaining new concepts. At the implementation stage, teacher did the following:

i. They had their students seated and asked them to keep quiet as they moved into groups. ii. Teachers generated interest and curiosity by asking thought provoking questions to lead the students into the activities.

The data collected from the administration of the instruments were analysed using the following statistical techniques:

i. Descriptive statistics, which involved the computation of the pre-tests, post-tests mean scores, standard deviation, and variance for each of the dependent variables.

ii. Analysis of Covariance (ANCOVA) computed for each dependent variable for the three instructional groups in order to test for possible post experimental differences in the dependent variables with respect to methods and anxiety. Multiple Classification Analysis (MCA) was used to determine the direction of the differences among the groups.

Computations for the afore-mentioned methods of data analysis were done using SPSS 15.00 statistical package.

\section{RESULTS AND DISCUSSION}

\subsection{Research Question 1}

Would there be any difference in the pre and post-test anxiety scores of students taught within the different strategies (5E, PDEODE \& Conventional Method)?

Table 1 revealed the students' Chemistry anxiety mean scores before and after exposure to the instructional strategies used in the study. The table showed that the 61 students exposed to ' $5 \mathrm{E}$ ' strategy recorded post-test mean Chemistry anxiety score of 24.79 (S.D. = 6.51); The 54 students exposed to PDEODE strategy recorded post-test mean anxiety score of 34.96 (S.D. = 15.01), while the 73 students exposed to conventional method recorded the highest posttest mean anxiety score of 42.14 (S.D. $=10.78$ ). Table 1 also revealed that the highest post-test anxiety score of 58 was obtained by a student exposed to conventional method of teaching while the least post-test anxiety score of 15 was obtained by two students (one exposed to conventional method and another exposed to PDEODE strategy). Table 1 further revealed negative mean anxiety values (reduced anxiety) across the three groups when the pre-test and post-test scores are compared; -3.36 for ' $5 \mathrm{E}$ ' strategy, -4.87 for PDEODE strategy and -2.11 
for conventional method respectively. This shows that the PDEODE strategy is better in reducing Chemistry anxiety than the other two strategies used in the study.

\subsection{Research Question 2}

Would there be any difference in the pre and post-test anxiety scores of students taught within the different strategies (5E, PDEODE \& Conventional Method) according to gender?

Table 2 revealed male and female students' mean Chemistry anxiety scores before and after exposure to the instructional strategies. The table showed that the 75 female students recorded post-test mean anxiety score of 35.01 (S.D. = 14.26) and that the 113 male students recorded reduced post-test mean anxiety score of 34.07 (S.D. = 12.63). The table also revealed that the highest post-test anxiety score of 58 was obtained by a male student while the least posttest anxiety score of 15 was obtained by two students (one male and one female). It further revealed reduced Chemistry anxiety across the two levels of gender when the pre-test and posttest scores are compared; -1.63 for the females and -4.43 for the males, thereby showing better reduction in Chemistry anxiety of the males than the female students.

\subsection{Research Question 3}

Would there be any difference in the pre and post-test anxiety scores of field dependent and field independent students taught within the different strategies (5E, PDEODE \& Conventional Method)?

Table 3 revealed the mean Chemistry anxiety scores of the sampled field dependent and the field independent students after exposure to the instructional strategies. The table showed that the 86 field dependent students recorded posttest mean anxiety score of 35.76 (S.D. = 13.31) and that the 102 field independent students recorded post-test mean anxiety score of 33.34 (S.D. = 13.21). The table also revealed that the highest post-test Chemistry anxiety score of 58 was obtained by a field independent learner while another field independent learner obtained the least post-test Chemistry anxiety score of 15 . It further revealed reduced Chemistry anxiety across the two levels of cognitive style when the pre-test and post-test scores are compared; -1.73 for the field dependent and -4.64 for the field independent learners, thereby showing better reduction in Chemistry anxiety of the field independent learners than the field dependent learners.

\subsection{Test of Hypotheses}

\subsubsection{Hypothesis $1\left(\mathrm{Ho}_{1}\right)$}

There is no significant main effect of instructional strategy (treatment) on senior secondary school students' Chemistry anxiety.

Table 1. Students' pre \& post-test chemistry anxiety scores according to strategy

\begin{tabular}{lllllll}
\hline Instructional strategy & N & Mean & S.D. & Minimum & Maximum \\
\hline ‘5E' strategy & Pre-test & 61 & 28.15 & 6.71 & 12 & 46 \\
& Post-test & & 24.79 & 6.51 & 17 & 48 \\
PDEODE strategy & Pre-test & 54 & 39.83 & 12.01 & 16 & 56 \\
& Post-test & & 34.96 & 15.01 & 15 & 57 \\
\multirow{2}{*}{ onvent. method } & Pre-test & \multirow{2}{*}{$*$} & 44.25 & 9.16 & 13 & 57 \\
\multirow{2}{*}{ Total } & Post-test & & 42.14 & 10.78 & 15 & 58 \\
& Pre-test & \multirow{2}{*}{188} & 37.76 & 11.64 & 12 & 57 \\
& Post-test & & 34.45 & 13.27 & 15 & 58 \\
\hline
\end{tabular}

Table 2. Students' pre \& post-test chemistry anxiety scores according to gender

\begin{tabular}{llllllll}
\hline Gender & & N & Mean & Mean gain & S.D. & Minimum & Maximum \\
\hline Female & Pre-test & 75 & 36.64 & -1.63 & 11.82 & 12 & 57 \\
& Post-test & & 35.01 & & 14.26 & 15 & 57 \\
Male & Pre-test & \multirow{2}{*}{113} & 38.50 & -4.43 & 11.51 & 13 & 56 \\
& Post-test & & 34.07 & & 12.63 & 15 & 58 \\
\multirow{2}{*}{ Total } & Pre-test & \multirow{2}{*}{188} & 37.76 & & 11.64 & 12 & 57 \\
& Post-test & & 34.45 & & 13.27 & 15 & 58 \\
\hline
\end{tabular}


Table 3. Students' pre \& post-test chemistry anxiety scores according to cognitive style

\begin{tabular}{llllllll}
\hline Cognitive style & & N & Mean & Mean gain & S.D. & Minimum & Maximum \\
\hline Field Dependent & Pre-test & 86 & 37.49 & -1.73 & 11.18 & 16 & 57 \\
\multirow{3}{*}{ Field Independent } & Post-test & & 35.76 & & 13.31 & 17 & 57 \\
& Pre-test & \multirow{2}{*}{102} & 37.98 & -4.64 & 12.06 & 12 & 56 \\
Total & Post-test & & 33.34 & & 13.21 & 15 & 58 \\
& Pre-test & \multirow{2}{*}{188} & 37.76 & & 11.64 & 12 & 57 \\
& Post-test & & 34.45 & & 13.27 & 15 & 58 \\
\hline
\end{tabular}

As presented in Table 4, the result revealed significant difference $\left(F_{(2,175)}=13.659, P<.05\right)$ in the post-test mean Chemistry anxiety scores of the students after exposure to the different levels of instructional strategy (5E, PDEODE and Conventional method). As a result, the null hypothesis $\left(\mathrm{Ho}_{1}\right)$ was rejected.
To explain which of the strategies recorded reduced Chemistry anxiety than the other, the magnitudes of the post-test mean Chemistry anxiety scores of the students exposed to the strategies in the study was computed and is presented in Table 5.

Table 4. Summary of analysis of covariance of students' chemistry anxiety scores according to treatment, gender and cognitive style

\begin{tabular}{|c|c|c|c|c|c|}
\hline Source of variation & Sum of squares & Df & Mean square & $\mathbf{F}$ & Sig. of $F$ \\
\hline Main effects & 3850.448 & 1 & 3858.448 & 34.305 & .000 \\
\hline Covariates (pre-test) & 2026.989 & 1 & 2026.989 & 18.059 & .000 \\
\hline Treatment (Strategy) & 3066.245 & 2 & 1533.123 & 13.659 & $.000^{*}$ \\
\hline Gender & 329.739 & 1 & 329.739 & 2.938 & .088 \\
\hline $\begin{array}{l}\text { Cognitive style } \\
\mathbf{2} \text { Way interactions }\end{array}$ & 13.266 & 1 & 13.266 & .118 & .731 \\
\hline Treatment * Gender & 183.482 & 2 & 91.741 & .817 & .443 \\
\hline Treatment * Cognitive style & 870.720 & 2 & 435.360 & 3.879 & $.022^{*}$ \\
\hline $\begin{array}{l}\text { Gender * Cognitive Style } \\
3 \text { Way interactions }\end{array}$ & .118 & 1 & .118 & .001 & .974 \\
\hline Treatmt * Gender * C. style & 55.800 & 2 & 27.900 & .249 & .780 \\
\hline Explained & 13304.147 & 12 & 1108.679 & 9.878 & .000 \\
\hline Residual & 19642.321 & 175 & 112.242 & & \\
\hline Corrected total & 32946.468 & 187 & & & \\
\hline
\end{tabular}

Table 5. Multiple classification analysis of students' chemistry anxiety scores according to instructional strategy (Treatment), gender and cognitive style Grand Mean = 34.14

\begin{tabular}{lllclc}
\hline $\begin{array}{l}\text { Variable + Category } \\
\text { instructional strategy }\end{array}$ & N & $\begin{array}{l}\text { Unadjusted } \\
\text { deviation }\end{array}$ & Eta & $\begin{array}{l}\text { Adjusted for independent } \\
\text { + Covariates }\end{array}$ & Beta \\
\hline 1.“5Es” Strategy & 61 & -10.14 & & -3.24 & \\
2.PDEODE Strategy & 54 & -3.59 & & 2.57 & .31 \\
3.Conventional Method & 73 & 3.68 & .09 & 10.73 & \\
Gender & & & & 4.36 & .10 \\
$\begin{array}{l}\text { 1. Female } \\
\text { 2. Male }\end{array}$ & 75 & -1.22 & & 0.70 & \\
Cognitive style & 113 & -3.89 & .01 & & .02 \\
1. Field Dependent & 86 & -2.10 & & 2.74 & .404 \\
2. Field Independent & 102 & -3.03 & .00 & 2.40 & .636 \\
Multiple R squared & & & & & \\
Multiple R & & & & & \\
\hline
\end{tabular}


The Multiple Classification Analysis in Table 5 revealed that with a grand mean of 34.14 , the students exposed to " 5 Es" strategy recorded the lowest post-test mean Chemistry anxiety score of 30.90. The students exposed to PDEODE strategy recorded the next lower post-test mean Chemistry anxiety score of 36.71 while the students exposed to conventional method recorded the highest post-test mean Chemistry anxiety score of 44.87 . This outcome thus revealed that " $5 \mathrm{E}$ " instructional strategy with the least post-test mean Chemistry anxiety score could reduce SSS students' Chemistry anxiety than PDEODE instructional strategy and the conventional method.

Table 5 further revealed that while instructional strategy alone contributed $31 \%$ of the variance in the students' Chemistry anxiety scores, the independent and moderator variables jointly accounted for $40.4 \%$ of the variance in the students' Chemistry anxiety scores.

To trace the source of the obtained significant difference, with respect to the null hypothesis (1), in Table 4, the Scheffe post-hoc analysis was computed and is presented in Table 4.

Table 6 revealed the pair-wise comparison of the students' post-test Chemistry anxiety scores on strategy using Scheffe test. The result revealed that the obtained significant difference was due to the significant difference in the post-test mean anxiety scores of the students exposed to the pairs of " $5 E s$ " strategy and PDEODE strategy, "5Es" strategy and Conventional Method and PDEODE strategy and Conventional Method. That is, the differences in the post-test mean anxiety scores of the students exposed to pairs of strategies mentioned are statistically significant at the .05 level of significance.

\subsubsection{Hypothesis $2\left(\mathrm{Ho}_{2}\right)$}

There is no significant main effect of gender on senior secondary school students' Chemistry anxiety.

The result of the main effect of gender on the SSS students' Chemistry anxiety in Table 4 revealed no significant gender difference $\left(F_{(1,175)}\right.$ $=2.938, P>.05)$. As a result, the null hypothesis $\left(\mathrm{Ho}_{2}\right)$ is not rejected. However, the result of the Multiple Classification Analysis (MCA) on gender in Table 5 showed that with a grand mean of 34.14 , the male students with post-test mean Chemistry anxiety score of 34.84 recorded reduced and lower Chemistry anxiety scores than the female students whose post-test mean Chemistry anxiety score was 38.50 . This outcome revealed that the magnitude of the posttest mean Chemistry anxiety score of the female students was higher than that of the male students but the difference in the mean scores is not statistically significant. Table 5 further revealed that gender alone accounted for $10 \%$ of the variance in the students' Chemistry anxiety scores.

\subsubsection{Hypothesis $3\left(\mathrm{Ho}_{3}\right)$}

There is no significant main effect of cognitive style on senior secondary school students' Chemistry anxiety.

The result of the main effect of cognitive style on the SSS students' Chemistry anxiety in Table 4 revealed no significant difference $\left(F_{(1,175)}=\right.$ $0.118, P>.05)$. Therefore, the null hypothesis $\left(\mathrm{Ho}_{3}\right)$ is not rejected. The result of the Multiple Classification Analysis (MCA) on cognitive style in Table 5 showed that with a grand mean of 34.14, the field dependent students recorded higher post-test mean Chemistry anxiety score of 36.88 than the field independent students who recorded post-test mean Chemistry anxiety score of 36.54. This outcome thus revealed that cognitive style does not have significant effect on students' Chemistry anxiety after exposure to the three levels of instructional strategy used in the study. Table 5 also revealed that cognitive style alone accounted for $2 \%$ of the variance in the students' Chemistry anxiety scores.

\subsubsection{Hypothesis $4\left(\mathrm{Ho}_{4}\right)$}

There is no significant interaction effect of treatment and gender on senior secondary school students' Chemistry anxiety.

Table 6. Scheffe Pair-wise comparisons of chemistry anxiety scores on treatment

\begin{tabular}{lllll}
\hline Mean & Instructional strategies & "5Es" & PDEODE & CM \\
\hline 24.79 & '5Es' strategy & & $*$ & $*$ \\
34.96 & PDEODE strategy & $*$ & & $*$ \\
42.14 & Conventional method & $*$ & $*$ & \\
\hline \multicolumn{4}{c}{ 'denotes pairs of groups that are significantly different at $P<.05$}
\end{tabular}


The result of the 2-way interaction effect in Table 4 revealed no significant interaction effect of treatment and gender on the students' Chemistry anxiety scores $\left(\mathrm{F}_{(2,175)}=.817, P>.05\right)$. That is, the effect of instructional strategy in reducing SSS students' Chemistry anxiety is consistent among the sampled male and female students. Therefore, the null hypothesis $\left(\mathrm{Ho}_{4}\right)$ is not rejected.

\subsubsection{Hypothesis $5\left(\mathrm{Ho}_{5}\right)$}

There is no significant interaction effect of treatment and cognitive style on senior secondary school students' Chemistry anxiety.

The result of the 2-way interaction effect in Table 4 revealed significant interaction effect of treatment and cognitive style (field dependent and field independent) on the students' Chemistry anxiety scores $\left(\mathrm{F}_{(2,175)}=3.879, P<\right.$ $.05)$. That is, the effect of instructional strategy in reducing SSS students' Chemistry anxiety is not the same among the sampled field dependent and field independent students. Therefore, the null hypothesis $\left(\mathrm{Ho}_{5}\right)$ is rejected.
This outcome, of significant 2-way interaction effect of treatment and cognitive style on the students' Chemistry anxiety scores, is further explained graphically using Fig. 1 to dis-entangle the source of the obtained significant interaction effect. The figure is necessary to pictorially depict which level of instructional strategy ('5Es', PDEODE and Conventional method) varies consistently or inconsistently with which level of cognitive style (field dependent and field independent).

The graph in Fig. 1 shows that whereas the sampled field independent students recorded higher post-test mean Chemistry anxiety scores than the field dependent students when exposed to '5Es' strategy and conventional method respectively, they recorded lesser post-test mean Chemistry anxiety scores when exposed to the PDEODE strategy, but the field dependent students on the other hand recorded higher posttest mean Chemistry anxiety scores than the field independent students when exposed to PDEODE strategy, while they recorded lower post-test mean Chemistry anxiety scores when exposed to '5Es' strategy and conventional method respectively.

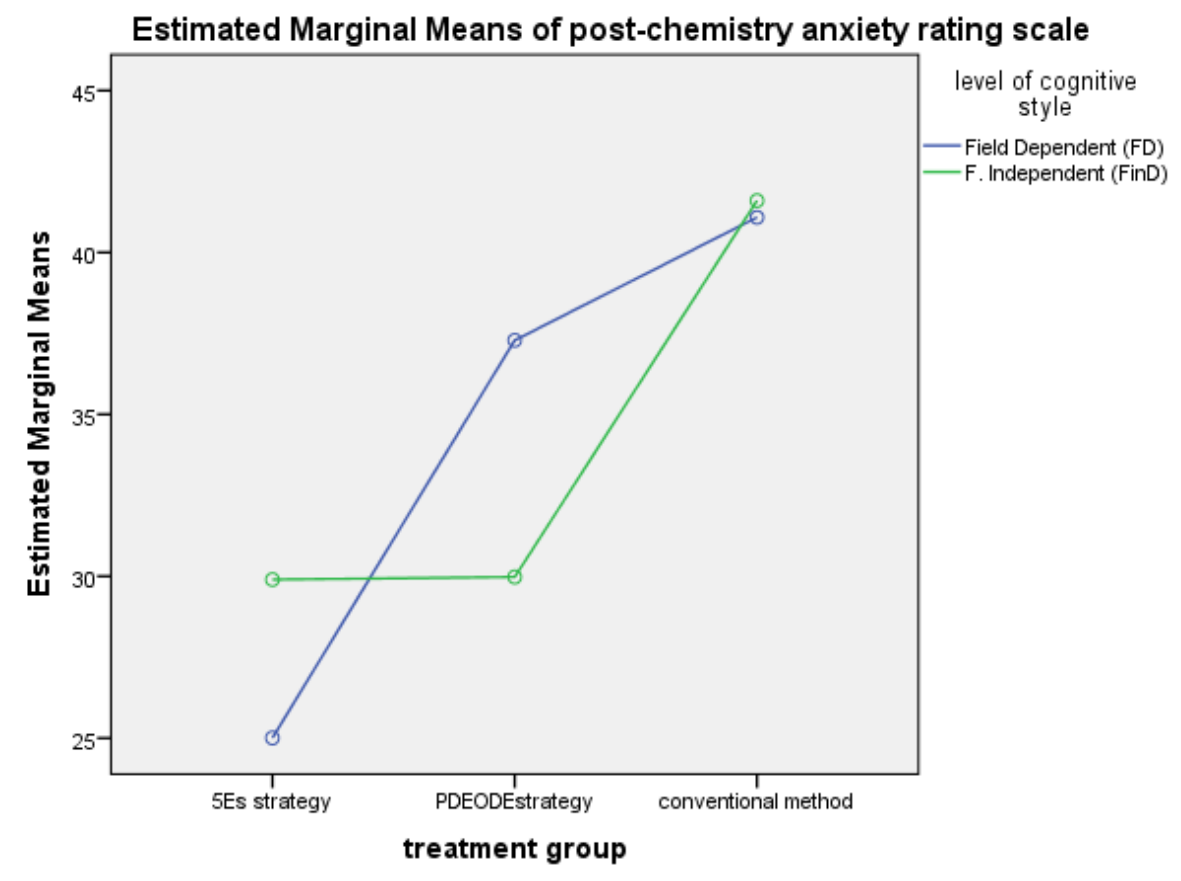

Covariates appearing in the model are evaluated at the following values: pre-chemistry anxiety $=37.76$

Fig. 1. Graphical Illustration showing 2-way interaction effect of treatment (Instructional Strategy) and cognitive style on students' chemistry anxiety scores 


\section{DISCUSSION OF FINDINGS}

Results from the aforementioned Tables 3 to 6 indicated that the three teaching methods used had effects on the anxiety scores of students in their groups at the post test level. This implies that post-test mean anxiety scores of chemistry students exposed to different treatment were significantly different (hypotheses 1). The MCA revealed that the students exposed to 5Es strategy recorded the lowest post-test mean chemistry anxiety score, followed by those exposed to PDEODE strategy, while the students exposed to conventional method recorded the highest post-test mean chemistry anxiety score. This outcome, thus, revealed that PDEODE instructional strategy with the average least posttest mean chemistry anxiety score can reduce Senior Secondary School students' chemistry anxiety, followed by the 5E strategy and, lastly, the conventional method. Plethora of studies $[9,35,36]$ ascertained that in a collaborative learning situation, when students work in groups, the focus of attention is diffused among the group members. When answer is presented to the class, it represents the work of the entire group; therefore, no individual student can be held up to criticism, hence the level of classroom anxiety is reduced. The findings of this present study confirms this, as the students exposed to 5Es and PDEODE strategies, which involves collaboration in practice, had a reasonable posttest mean chemistry anxiety score compared to the conventional method. The post-test mean anxiety scores of the field dependent and field independent learners were not significantly different after exposure to the different instructional strategies. Also, treatment interact with students' level of cognitive style in determining students' anxiety in chemistry. The differences in post-test mean chemistry anxiety scores of students in the two cognitive style levels (field dependent and field independent) in respect of $5 E$ and PDEODE groups were very close. This suggests that students at the two levels of cognitive style experienced reduced anxiety when taught with the study strategies (5E and PDEODE). The field dependent learners experienced reduced anxiety within the $5 \mathrm{E}$ model, while the field independent learners experienced reduced anxiety within the PDEODE model. Literatures on the influence of cognitive style on Senior Secondary School students' learning outcomes contain contradictory results. While [37] showed that field independent learners are generally superior to their field dependent counterparts in learning outcomes,
[38] including this present study, did not find either style performing better than the other. These inconsistences arose probably because studies were conducted with students of different classes on different science content areas and under different testing formats. The group work in this study experimental groups (5E and PDEODE) favoured both Field-Dependent and Field-Independent students. This could be that the learning environment within this study was not interpreted as a threat by the learners, hence disallowing anxiety, as suggested by [39].

There was no significant main effect of gender on the students' chemistry anxiety scores. This corroborated the findings of $[40,41,42]$ that there are no longer distinguishing differences in science learning outcomes of students in respect of gender. Also, this study revealed that treatment (PDEODE, 5E and CM) did not interact with gender in determining student' chemistry anxiety, meaning that no treatment was superior over the other for any of the gender groups for chemistry anxiety. Finally, findings revealed lack of significant interactions between treatment, gender, cognitive style and anxiety. This indicates that 5E and PDEODE learning models are not differentially effective for learners' anxiety towards chemistry for different cognitive styles and genders.

\section{CONCLUSION}

This study has very important contributions and high implication for the educational practices in Nigeria. There were negative mean anxiety values (reduced anxiety) across the three groups when the pre-test and post-test scores were compared; -3.36 for ' $5 \mathrm{E}$ ' strategy, -4.87 for PDEODE strategy and -2.11 for conventional method respectively. The PDEODE model have significantly higher tendency of reducing anxiety towards chemistry than the $5 \mathrm{E}$ model and the Conventional Method (CM). This implies that the two learning models (PDEODE and 5E) have been effective and can be recommended for use in the teaching and learning of chemistry concepts.

Based on these findings, the following recommendations are made:

1. The Science Teachers' Association of Nigeria (STAN), Chemistry Teacher Association and other relevant academic societies responsible for teaching of chemistry should endeavour to popularize 
the adoption of 5E and PDEODE strategies in their teaching.

2. The utilization of these strategies in the chemistry classroom will necessitate significant role change for teachers. Therefore, there is need to train practicing teachers and also pre-service teachers to carry out these new roles; incorporating day-to-day activities that relates to chemistry into lesson plan; relating learning task and learning materials to learners' immediate environment.

\section{COMPETING INTERESTS}

Authors have declared that no competing interests exist.

\section{REFERENCES}

1. Okebukola PA. Towards a national strategic vision for Nigerian Universities. A report presented at the 2014 executive education programme for vice-chancellors organised by the association of vicechancellors of Nigerian Universities, Uyo. 2014;19-20.

2. Alebiosu KA. Cooperative learning and students' affective learning outcomes in Nigerian chemistry classroom. Ife Psychologia. An International Journal. 2001;9(2):135-14.

3. Andreas K, Manfred P. Research on interest in science: Theories methods and findings. International Journal of Science Education. 2011;1(1):27-50.

4. Ayelet B, Yarden A. Identifying metaclusters of students' interest in science and their change with age. Journal of Research in Science Teaching. 2009; 46(9):999-1022.

5. Akbas A, Kan A. Affective factors that influence chemistry Achievement (Motivation and anxiety) and the power of these factor to predict chemistry Achievement-II. Journal of Turkish Science Education. 2007;4(1):10-19.

6. Chen Chong $\mathrm{SH}$. assessment of chemistry anxiety among college students. In: Chiu $\mathrm{MH}$, Tuan HL, Wu HK, Lin HK, Chou CC. (Eds.) Chemistry Education and Sustainability in the Global Age; 2013.

7. Eddy RM. Chemophobia in the college classroom: Extent, sources and student characteristics. Journal of Chemical Education. 2000;77(4):514-517.

8. Jegede SA. Students' anxiety towards the learning of chemistry in some Nigerian secondary schools. Educational Research and Review. 2007;2(7):193-197.

9. Oludipe D, Awokoya JO. Effect of cooperative learning teaching strategy on the reduction of students' anxiety for learning chemistry. Journal of Turkish Science Education. 2010;7(1):34-42.

10. Cheung D. Confirmatory factor analysis of the attitude toward chemistry lesson scale. Proceeding of the $2^{\text {nd }}$ network for interasian chemistry educators. Taipei, Taiwan; 2007.

11. Barlow DH, Durand VM. Abnormal psychology: An integrative approach. Belmount, California: Wardsworth/Centage learning; 2009.

12. Bilesanmi-Awoderu JB. Methods and techniques of teaching. In; Erinosho, Adesanya and Ogunyemi (Eds.). Teaching Effectiveness in Nigeria Schools; 2000.

13. Bilesanmi-Awoderu JB. Effects of computer-assisted instruction and simulation / games on the academic achievement of secondary school students in biology. Sokoto Education Review. 2006;8(1):1-11.

14. Ibe $E$. Breaking gender barriers in achievement in STME using hands - on, minds - on science: Implication for supply of resources. $49^{\text {th }}$ Annual Conference Proceeding of Science Teachers Association of Nigeria. 2005;211-214.

15. Danmole BT, Femi-Adeoye KO. Effect of concept mapping technique on senior secondary school students' achievement and retention of ecology concepts. Journal of the Science Teachers Association of Nigeria. 2004;39(1-2):32-37.

16. Alebiosu KA. Sustaining the participation and achievement of secondary school girls in practical chemistry through the STAD model. Journal of Educational Focus. 2000;2(2):112-116.

17. Alebiosu KA. Using questioning and answering strategy to enhance students' learning and retention of organic chemistry concepts. Nigeria Journal of Advanced Research in Education. 1997;1(1):88-96.

18. Science Teachers Association of Nigeria. Linking school chemistry with learners day- 
to-day activities. Chemistry panel series 4 . A handbook for chemistry teachers. In: Olayiwola MA, Walter SU (Eds.); 2009.

19. Campbell B, Lubben F. Learning science through contexts: Helping pupils make sense of everyday situations. International Journal of Science Education. 2000;22(3): 239-252.

20. Harlen W. Links to everyday life: The roots of scientific literacy. Primary Science Review. 2002;71:8-10.

21. Smith PJ, Disessa AA, Rochelle J. Misconceptions reconceived: A constructivist analysis of knowledge in transition. The Journal of the Learning Sciences. 1993;3(2):115-163.

22. Costu B. Learning science through the PDEODE teaching strategy: Helping students make sense of everyday situations. Eurasia Journal of Mathematics, Science \& Technology Education. 2008; 4(1):3-9.

23. Urek $H$, Dolu $G$. Knowledge level of teacher candidates about elements and Compounds in daily life. Journal of Educational and Instructional Studies in the World. 2013;3(1):205-212.

24. Bybee RW, Taylor JA, Gardner A, Van Scotter P, Powell JC, Westbrook A, Landes $\mathrm{N}$. The BSCS $5 \mathrm{E}$ instructional model: Origins, effectiveness and applications. Colorado Springs. BSCS; 2006.

25. Eisenkraft A. Expanding the $5 \mathrm{E}$ model. Science Teacher. 2003;70(6):56-59.

26. Eren C, Omer G. Facilitating conceptual change in understanding state of Matter and solubility concepts by using $5 \mathrm{E}$ Learning cycle model. Hacettepe University Journal of Education. 2009;36: 41-50.

27. Balci S, Cakiroglu J, Tekkaya C. Engagement, exploration, explanation, Extension and evaluation (5E) learning cycle and conceptual change text as learning tools. Biochemistry and Molecular Biology Education. 2006;34:199-203.

28. Liu TC, Peng $\mathrm{H}, \mathrm{Wu} W H$, Lin MS. The effect of mobile natural-Science Learning based on the 5E Learning cycle: A case study. Educational Technology \& Society. 2009;12(4):344-358.

29. Posner GJ, Strike KA, Hewson PW, Gertzog W. An accommodation of a scientific conception: Toward a conceptual change. Science Education. 1982;66:211227.

30. Costu B, Ayas A, Niaz M. Promoting conceptual change in first year students understanding of evaporation. Chemical Education Research and Practice. 2010; 11:5-16.

31. Costu B, Ayas A, Niaz M. Investigating the effectiveness of a POE-based teaching activity on students' understanding of condensation. Journal of Instructional Science. 2012;40(1):47-67.

32. Mohammad Khair A. The effectiveness of using (PDEODE) strategy among higher basic stage students on their achievement of physics concepts and scientific thinking. An-Najah University Journal for Research Humanities. 2012;26(9):2041-2064.

33. Al-Khateeb M. The effect of the constructivist based instructional strategy (PDEODE) on developing Tenth Graders' mathematical thinking, comprehension and retention of mathematical concepts. DIRASAT. Educational Sciences. 2012; 39(1):75-83.

34. Witkin HA, Oltman PK, Raskin E, Karp S. A manual for the group embedded figure test. Palo Alto, California. Consulting Psychologists Press; 1971.

35. Ogundokun MO. Learning style, school environment and test anxiety as correlates of learning outcomes among secondary school students. IFE Psychologia. 2011; 2(19):321-331.

36. Bilesanmi-Awoderu JB, Oludipe DI. Effectiveness of cooperative learning strategies on Nigerian junior secondary students' academic achievement in basic science. British Journal of Education, Society \& Behavioural Science. 2012;2(3): 307-325.

37. Umaru Y, Tukur HA. The influence of dependent and independent cognitive styles on achievement in mathematics among senior secondary school students in Bida Educational Zone of Niger State, Nigeria. Journal of Research in Education and Society. 2013;4(2):63-72.

38. Altun A, Cakan M. Undergraduate students' academic achievement, field dependent/independent cognitive styles and attitude toward computers. Educational Technology \& Society. 2006; 9(1):289-297. 
39. Hoehn-Saric R, McLeod DR. Anxiety and arousal: Physiological changes and their perception. Journal Affect Disord. 2000; 61:217-224.

40. Achor EE, Kurumeh SM, Orokpo CA. Gender dimension in predictors of students' performance in MOCK-SSCE practical and theory chemistry examinations in some secondary schools in Nigeria. Education. 2012;2(2): 16-22.
41. Afuwape MO, Oludipe DI. Gender differences in integrated science achievement among pre- service teachers in Nigeria. Educational Research and Review. 2008;3(7):242-245.

42. Adesoji FA, Babatunde AG. Expressive teaching behaviour: Bridging the gender gulf in secondary school chemistry achievement. International Journal of African \& African American Studies. 2005; $4(1): 54-61$.

(0) 2017 Alebiosu et al.; This is an Open Access article distributed under the terms of the Creative Commons Attribution License (http://creativecommons.org/licenses/by/4.0), which permits unrestricted use, distribution, and reproduction in any medium, provided the original work is properly cited.

Peer-review history:

The peer review history for this paper can be accessed here: http://sciencedomain.org/review-history/19406 